\title{
Mitteilungen der Schriftleitung
}

Sehr geehrte Kolleginnen und Kollegen,

in diesem Heft findet sich zum ersten Mal im Gegensatz zur bisherigen Strategie, gleichsam als Pilotprojekt, ein Aufsatz, dessen Thema nicht aus dem Gebiet der Versicherungs- oder Bausparmathematik bzw. deren engeren Umkreis stammt, der vielmehr ein Thema aus einem Gebiet behandelt, das, wie ich meine, für die Versicherungsmathematiker immer bedeutsamer wird: das Gebiet der Datenverarbeitung und seine Anwendung in der Versicherungstechnik. Ich ließ mich davon überzeugen, daß es für die Mitglieder der DGVM von Vorteil sei, wenn auch DV-Anwendungen mit versicherungsmathematischem und versicherungstechnischem Bezug in den Blättern behandelt würden. Ich wäre sehr dankbar, hierzu Ihre Meinung zu hören.

Ihr Neuburger 